\title{
Verbal Orders in Medicine: Challenges; Problems and Solutions
}

\author{
Hamid Moghaddasi ${ }^{1}$, Mohammad Farahbakhsh ${ }^{2}$ and Hanieh Zehtab ${ }^{1 *}$ \\ ${ }^{1}$ Department of Health Information Technology and Management, Faculty of Paramedical Sciences, Shahid Beheshti University of Medical Sciences, \\ Tehran, Iran
}

${ }^{2}$ Department of Infectious Diseases, Faculty of Medicine, Shahid Beheshti University of Medical Sciences, Tehran, Iran

Submission: April 18, 2017; Published: May 25, 2017

*Corresponding author: Hamid Moghaddasi, Department of Health Information Technology and Management, Faculty of Paramedical Sciences, Shahid Beheshti University of Medical Sciences, Tehran, Iran, Tel: 0098-21-22747373;

Email: Zehtab@behdasht.gov.ir

\section{Abstract}

Introduction and objective: Despite the many advantages of a verbal order, some disadvantages have been identified with this method. This study examines the problems encountered through the use of verbal orders and the various solutions offered to reduce the clinical errors caused by such method.

Methods: 83 articles published in English between 2000 and 2016 were extracted from Pubmed, Pro-Quest, Google Scholar, and Science direct databases. After a qualitative review of these articles, 32 of them were selected that were relevant to the objective of this study.

Background: Most of the aspects of verbal orders that have been studied include: the process of providing verbal orders and reason for errors, competency of the individuals who prescribe and receive verbal orders, method of documentation, limitations, authorization \& validation, strategies, techniques and specific measures to enhance transparency and effectiveness, considering two characteristics of the content and context.

Results: The most common recommendations for the paper method in order to reduce errors are to restrict the use of this kind of order and/or to repeat the order. Computerized Physician Order Entry (CPOE) \& mobile CPOE tools are among the recommended health information technology solutions that not only increase the efficiency of the order process but also support the displacement of verbal prescribers.

Conclusion: The use of mobile-based information systems is on the rise because they are more flexible and allow greater mobility to the users compared to other information systems. Furthermore, mobile-based information systems can collect, store and analyze the detailed information of verbal orders in a more efficient way.

Keywords: Electronic clinical documentation; Communication; Computerized physician order entry systems

\section{Introduction}

One of the effective communication tools between members of the healthcare team is medical orders forms; it is necessary for the healthcare team members to exchange information while working. This information can be direct (for example, verbal conversations) or indirect (e.g. entering data into health information systems). Verbal order is common as an informal communication tool between doctors and nurses and increases interoperability between them [1].

National Coordinating Council for Medication Error Reporting and Prevention (NCC MERP), defines medication errors of verbal orders as medication orders which are provided face-to-face or, by phone or through other voice communication means [2]. These kind of orders are often used when prescribers, including physicians or physician assistants, are unable or unwilling to write patient care orders [3]. Verbal orders have been common, since earlier times, as a method of communication and are used in different health areas, including hospitals, nursing homes, clinics and hospice. In non-office hours, verbal orders are one of the most common methods of communication [4]. In addition to using other communication technologies such as phone, fax, and email, SMS is also used in $84.1 \%$ of verbal orders. It is estimated that, in more than $20 \%$ of cases, medical orders in hospitals are given orally. These verbal orders can be an order or series of orders during an ordering event (for example, ordering a laboratory test, discontinuing one medication, and starting a second medication) and may cover all types of orders (e.g., diagnostic tests, clinical counseling, medications and other therapeutic interventions) [5]. If the orders are received by a competent and authorized person, then 
the decision will be timely and more reliable and will accelerate the work; and, if they are duly signed, these orders become legal. The important thing is that, basically, these types of orders have error potential. The factors that cause the error in the verbal orders include: fatigue of prescriber or order receiver, similarity of the names of drugs, noise in the environment, accents, dialects, spelling differences, unfamiliarity with conditions and the patient's condition, and unfamiliar terms [6].

A study by Chu et al. [7] indicates that, in 19\% of errors in the field of medicine, $2.3 \%$ are related to verbal orders [7]. Therefore, this method should be used only in emergency conditions and, where not possible, to write the order, or to enter information into the computer; for example, when a doctor is involved in surgery or treatment and where it is not possible to interrupt him/her [8].

The «The Joint Commission for the Accreditation of Healthcare Organizations» (JCAHO) also confirms that the use of verbal orders certainly cannot be banned, but its use can be minimized [9]. It can be used at certain times; so, although verbal orders are problematic because of audio issues, etc., care centers will continue to use the verbal order method now and in the not too distant future; this is because of the distance between the place where the orders are given and where the information is entered electronically, clinical necessity or prescriber preference and convenience [10]. The use of verbal orders has problems in addition to its advantages and efforts are being made to fix them. The aim of this study was to address the problems, challenges and different solutions offered to reduce the error caused by the verbal order.

\section{Methods}

In line with the objectives of the study, a total of 670 articles in English published from 2000 to 2016 were extracted through a comprehensive and detailed review of the scientifically valid publication databases like Science direct, Pubmed, ProQuest and Google Scholar. At this stage, after re-examining and removing unrelated articles, 83 articles remained. Inclusion criteria for the study were based on their relationship with the aim of the study and subject relation. To investigate the quality of the articles in possession, they were evaluated in terms of title, abstract, introduction, research method, results, discussion and references. After final assessment, 32 selected articles were carefully studied and the content, were developed in a proper sequence to meet the goal of the study.

\section{Background}

As mentioned above, verbal orders have been identified as a risk factor for the patients and, when combined with the pressure of overwork and inexperience of staff, the possibility of error increases.

It is necessary for healthcare institutions to perform actions while using these orders to reduce errors. Some common errors in using verbal orders include: incorrect expression of patient's status, naming similarity of the patients, making the wrong decision, no request for clarification, confusion and/or not read back the verbal order, errors in prescription writing.

Recipients of verbal orders might make mistakes in the audition, understanding and writing of orders, or Misunderstand sound- a like medication. In addition to the names of drugs, mistakes might occur in dosage or drug usage. Several examples of errors in the use of this type orders have been reported [10].

In multilingual environments, there is a possibility of misunderstanding verbal orders [11]; also, due to the use of masks by doctors, the order may be heard wrongly [12]. Thus, in order to minimize errors and injuries related to the issuing of verbal orders, recommendations have been proposed by authorities and various organizations, including the National Coordinating Council for Medication Error Reporting and Prevention (NCC MERP).The most commonly recommended method to reduce verbal order error, and to increase the validity and reliability of documentation processes, is the read back method. All orders must be recorded and registered by nurses who receive the order and then should request the doctor to repeat the order. The doctor should also repeat it to him/herself [13]. The recipient of the order should announce more complete information about the patient's history and the medications consumed and the prescriber must sign it within the following 48 hours [6,14-16].Sometimes in the healthcare system this is not done for the following reasons [6]:

A. Misunderstanding of medications with similar names.

B. Fear of incompetence in the view of the other person.

C. Possible negative response of the prescriber.

D. Inadequate number of employees relative to the workload.

E. Previous experience between prescriber and order receiver in working together.

According to a study conducted by Rask et al. [17], although most hospitals had a read back policy for verbal order, only $36 \%$ of them have policies and procedures to reduce verbal orders [17].

Restrictions are also applied to prohibit the use of verbal orders in order to prescribe high-alert drugs such as Thrombolytic or Heparin [9].

The policy of not accepting verbal chemotherapy orders is becoming common in the field of healthcare. Most available studies have investigated the following items in verbal orders:

A. The times of use or non-use of verbal orders [18].

B. The persons authorized to prescribe and receive verbal orders. 
C. The process of providing verbal orders and the reasons for their error.

D. The essential items in the registration of contents of verbal orders.

E. Limitations and restrictions on the use of verbal orders.

F. How is the authorization and validation of the verbal orders defined?

G. What are the strategies, techniques and specific measures to enhance the transparency and effectiveness of verbal orders? [19]

H. Requirements for the periodic monitoring and evaluation of verbal orders and their compliance with organizational policies and procedures $[6,15,20]$.

I. Attending two features of the content and context in verbal orders that can be the cause of the error.

Recommendations that have commonly been given in the use of verbal orders in healthcare include:

A. Oral communication should only be used in emergency situations $[21,22]$, where it is not possible to write or input information into the computer [6], (e.g. when the prescriber is in a sterile environment) [14].

B. Policies and procedures in health centers to restrict and prohibit the use of verbal orders[19].

C. Providing a process to ensure the legality of the physician in providing verbal orders.

D. Explaining the situation in which verbal orders were used.

E. Determination of authorized recipients and prescribers of verbal orders.

F. Providing guidelines for clear and effective communication in verbal orders.

a. For example, the prescriber and the recipient of the prescription can spell out the names of unfamiliar drugs letter by letter [14,23].

G. Immediate registration and signing of verbal orders by the person receiving the order.

H. Reviewing and signing the verbal orders recorded in the medical records of patients as soon as possible.

I. Identification of components that must be included in verbal orders $[15,23]$.

J. Review and verification of verbal orders when the recipient of the order does not have enough experience [22].

Two characteristics of verbal orders that can be the cause of errors include the content and context of the verbal orders. The content of verbal orders refers to the number and type of each instruction given orally. The text of the verbal orders relates to the general condition or situation that the verbal orders are made under, the conversation process and confirmation and rewriting the orders. The content of verbal orders regarding hospitalized patients has many complications that may cause the error. Examples of content variables in verbal orders include: the number of orders, different types of orders (for example, pharmacy, laboratory, radiology), the complexity of orders, urgency of orders, non-standard abbreviations and terminology, the use of drugs with similar names, dosages of high-alert drugs.

Environmental variables regarding verbal orders are as follows: type of place providing healthcare, timing communication processes, multiple methods of communication, noise levels in the environment, the characteristics of employees, level of familiarity of the providers and recipients of verbal orders with the patient, differences in intelligence of providers and recipients of orders, differences in language skills and clarity of communications of each of the speakers of verbal orders [10].

To find a solution to reduce the harms of verbal orders before the intervention, a greater understanding of the complexity of these orders, and how this complexity may lead to an increase in injury or mistake, and to identify the effective tools, are required to ensure proper verbal orders, and to use them correctly [2].

One of the factors that could be the cause of problems is a delay in signing the documentation on the part of the physician [24]. In order to solve this problem, the training of medical assistants to get them to complete documentation has been emphasized. Also, in some cases, nurses are not aware of the rules and guidelines of verbal orders; in this regard, training and awareness among the nurses is emphasized [25].

Besides the different methods proposed to achieve the patient's safety in manual systems, the use of information technology is considered as an appropriate approach to provide safe care and to reduce the risks involved in healthcare. According to the National Quality Forum (NQF), one effective way to improve patient safety, and which should be prioritized in this research, is the use of computerized physician order entry (CPOE) instead of verbal orders.

Brunt et al. [26] study shows that, after the implementation of Tele CPOE, the number of verbal orders has decreased. Non-compliance and lack of complete documentation are the problems encountered in the use of this system. Yeon Kim et al. [27] study proves that, by using CPOE, the completed documentation for laboratory orders demanded verbally has reached $100 \%$ and this computerized process has been accepted by healthcare providers [27]. Implementing this system at the Children's Hospital in Pittsburgh as a compliance of verbal orders has increased from $80 \%$ to $95 \%$ [28]. 
An example of the difficulties experienced in verbal order data entry after implementing CPOE is as follows: A nurse, when selecting the physician's name from the list of doctors, chooses a physician's name by mistake and the doctors were faced with orders that were associated with his name. However, they did not implement healthcare measures for the patient. To solve this problem, the nurses were trained in the importance of choosing the right name of the doctor and, therefore, its importance was noted. In addition, it was redesigned so that, when choosing the name, a new page is displayed and the nurse is asked again about the accuracy of physician's name [29].

Electronic systems have been implemented to stop the use of verbal orders. However, in certain circumstances, when using $\mathrm{CPOE}$, it is observed that healthcare providers are forced to bypass it and verbal orders are often still used [30].

Note that one of the reasons for using verbal orders is the mobility of care providers, because patients and health sectors are not accessible in one place and at the same time. On the other hand, mobile phones are now advanced communication devices that have high processing powers and provide a quick and easy connection; they also enable access to data wherever possible, quickly and easily.

In order to increase efficiency and mobility, Wookjin Choi et al. [31] have designed a mobile-based Electronic Health Records (EHR) application. One of the components of this software is verbal order exchange [31]. Zarka et al. [19] have designed a mobile-based computerized physician order entry application called Patient Keeper, which provides access to patient medical data. One of its objectives is to reduce verbal orders.

In using electronic documentation tools, including CPOE or EHR, it is important to note that, if these means are more up-todate and make it possible to store the verbally exchanges data, then they will increase the effectiveness of communication [32].

In 2009, Mendel and Kohan found that the clinical implications are due to the inflexible design of EHR. The possibility of integrating and quick access to data on the organization's information systems is provided by mobile developers who are inspired by the agile methods and design high quality, applied mobile applications [33].

\section{Results}

As mentioned above, verbal order is considered an important communication mechanism in healthcare systems but which, for various reasons, can lead to errors and impact patient safety and quality of healthcare. Since it is not possible to eliminate this method of communication, solutions have been provided to reduce errors in the use of this method. The findings from the study show that the proposed solutions to mitigate existing problems can be divided into two groups: paper-based and electronic.
In the standards and clinical guidelines on the use of verbal orders, it is emphasized that healthcare provider organizations should apply policies and procedures to limit verbal orders and to use the read back method. This will increase the clarity and accuracy of this type of order, where the verbal order process is clearly described and a process is expressed to ensure the people who are entitled to receive the orders and components and documentation method are properly advised. This method should also be utilized by care providers, including doctors and nurses, who should have adequate knowledge about the instructions and follow them. Also, in residency training, appropriate education to complete and sign documents in a timely fashion could form their appropriate professional behavior so that doctors are obliged to observe these items.

According to the increased use of computerized systems by healthcare provider organizations, solutions have been provided to reduce the use of verbal orders in this way. Many studies have introduced Tele CPOE and mobile-based CPOE as solutions to increase the efficiency and to support the shift of verbal order prescribers.

Numerous studies have examined the impact of computer systems on verbal orders. The results indicate that, by implementing the computer systems, the following issues have declined:

A. The number of verbal orders $[18,34,35]$.

B. The interval between verbal orders of doctors to its signing.

C. The number of unsigned orders.

D. Incompatibility of verbal orders [36].

Although, in many studies, the positive impact of computerized systems on verbal orders has been studied, in certain circumstances, healthcare providers are forced to bypass it. Also, the use of this type of order is common in clinical environments.

\section{Conclusion and Suggestion}

The results of this study indicate that the use of verbal orders, in spite of its advantages, is considered as the cause of errors in the process of providing healthcare. Therefore, reviewing and updating policies in the healthcare centers is essential to ensure the proper implementation of orders and optimizing patient safety and reducing healthcare concerns.

One reason for the use of verbal orders is the absence of the physician in the healthcare organization, especially in non-working hours, thus causing a lack of access and lack of attention to the patient care data. Therefore, information technology, especially CPOE, can reduce the amount of verbal orders and the errors. Moreover, with the rapid growth of mobile-based information systems, the ability to design and 
develop information systems is much more flexible compared to traditional information systems. Mobile-based information systems will give users more mobility and the use of these systems will provide the ability to collect; analyze and store detailed information of verbal orders, in a more updated and effective form. For the convenience of mobile the fore mentioned problem will be solved through applying CPOE by doctors.

\section{References}

1. Pirnejad H, Niazkhani Z, van der Sijs H, Berg M, Bal R (2009) Evaluation of the impact of a CPOE System on Nurse-physician communication. Meth Info Med 48(4): 350-360.

2. Kaplan JM, Ancheta R, Jacobs BR (2006) Inpatient verbal orders and the impact of computerized provider order entry. J Pediatr 149(4): 461-467.

3. Wakefield DS, Wakefield BJ, Despins L, Brandt J, Davis W, et al. (2012) A review of verbal order policies in acute care hospitals. Jt Comm J Qual Patient Saf 38(1): 24-33.

4. Gregory A, Todd J, Wanklyn S (2007) Out-of-hours prescribing: a survey of current practice in the UK. Palliat Med 21(7): 575-580.

5. Wakefield DS, Clements K, Wakefield BJ, Burns J, Hahn-Cover K (2012) A framework for analyzing data from the electronic health record: verbal orders as a case in point. Jt Comm J Qual Patient Saf 38(10): 444-451.

6. Wakefield DS, Wakefield BJ (2009) Are verbal orders a threat to patient safety? Qual Saf Health Care 18(3): 165-168.

7. Cho I, Park H, Choi YJ, Hwang MH, Bates DW (2014) Understanding the nature of medication errors in an ICU with a computerized physician order entry system. PLoS One 9(12): e114243.

8. Tuohy N, Paparella S (2005) Look-alike and sound-alike drugs: errors just waiting to happen. J Emerg Nurs 31(6): 569-571.

9. Paparella S (2004) Avoid verbal orders. J Emerg Nurs 30(2): 157-159.

10. Wakefield DS, Brokel J, Ward MM, Schwichtenberg T, Groath D, et al. (2009) An exploratory study measuring verbal order content and context. Qual Saf Health Care 18(3): 169-173.

11. Kizer KW, Blum LN (2005) Safe practices for better health care.

12. Institute for Safe Medication Practices (2015) ISMO's list of confused drug names.

13. Mayhew M (2006) What a Person Can Do to Help Increase Medication Safety. The Journal for Nurse Practitioners 2(10): 705-707.

14. MR Cohen (2007) Medication errors: American Pharmacist Association, Washington, USA.

15. Recommendations to Reduce Medication Errors Associated with Verbal Medication Orders and Prescriptions (2006) The National Coordinating Council for Medication Error Reporting and Prevention (NCC MERP).

16. Westrick SJ (2013) Essentials of nursing law and ethics: Jones \& Bartlett Publishers, USA.

17. Rask K, Culler S, Scott T, Kohler S, Hawley J, et al. (2007) Adopting National Quality Forum medication safe practices: Progress and barriers to hospital implementation. J hosp med 2(4): 212-218.
18. Mekhjian HS, Kumar RR, Kuehn L, Bentley TD, Teater P, et al. (2002) Immediate benefits realized following implementation of physician order entry at an academic medical center. J Am Med Inform Assoc 9(5): 529-539.

19.Zarka N, Hinnawi MF, Dardari A, Tayyan MA (2004) Patient Keeper medical application on mobile phone. 37-38.

20. Srirama SN, Matthias J, Wolfgang P (2006) A Mediation Framework for Mobile Web Service Provisioning. Enterprise Distributed Object Computing Conference Workshops, EDOCW, USA, pp. 14.

21. Cohen MR (2007) Association, Medication Errors: American Pharmacists Association, USA.

22. Kelly WN (2004) Medication Errors Lessons learned and actions needed.

23. Koczmara C, Jelincic V, Perri D (2006) Communication of medication orders by telephone-writing it right. Dynamics 17(1): 20-24.

24. Hsieh SH, Hou IC, Cheng PH, Tan CT, Shen PC, et al. (2010) Design and implementation of web-based mobile electronic medication administration record. J Med Syst 34(5): 947-958.

25. Kim Y, Kim SS, Kang S, Kim K, Kim J (2014) Development of Mobile Platform Integrated with Existing Electronic Medical Records. Healthc Inform Res 20(3): 231-235.

26. Brunt BA, Gifford IL (2009) Patient safety, quality care, and service utilization with PLATO (Physician Leadership for Accurate and Timely Orders): a pilot study. J Nurses Staff Dev 25(4): E11-E18.

27. Kim JY, Kamis IK, Singh B, BatraS, Dixon RH, et al.(2011) Implementation of computerized add-on testing for hospitalized patients in a large academic medical center. Clin Chem Lab Med 49(5): 845-850.

28. Upperman JS, Staley P, Friend K, Neches W, Kazimer D, et al. (2005) The impact of hospitalwide computerized physician order entry on medical errors in a pediatric hospital. J Pediatr Surg 40(1): 57-59.

29. Gellert GA, Hill V, Bruner K, Maciaz G, Saucedo L, et al. (2015) Successful Implementation of Clinical Information Technology: Seven Key Lessons from CPOE. Appl Clin Inform 6(4): 698-715.

30. Mosa AS, Yoo I, Sheets L (2012) A systematic review of healthcare applications for smartphones. BMC Med Inform Decis Mak 12(1): 67.

31. Choi W, Park MA, Hong E, Kim S, Ahn R, et al. (2013) Development of mobile electronic health records application in a secondary general hospital in Korea. Healthc Inform Res 19(4): 307-313.

32. Collins SA, Bakken S, Vawdrey DK, Coiera E, Currie L (2011) Clinician preferences for verbal communication compared to EHR documentation in the ICU. Appl Clin Inform 2(2): 190-201.

33. Mandel JC, Kreda DA, Mandl KD, Kohane IS, Ramoni RB (2016) SMART on FHIR: a standards-based, interoperable apps platform for electronic health records. J Am Med Inform Assoc 23(5): 899-908.

34. Improving the Safety of Telephone or Verbal Orders (2006) The Pennsylvania Patient Safety Authority And Its Contractors.

35. Payne KB, Wharrad H, Watts K (2012) Smartphone and medical related App use among medical students and junior doctors in the United Kingdom (UK): a regional survey. BMC Med Inform Decis Mak 12: 121.

36. Karson AS, Campbell EJ, Panagou CM, Gurevich P, Chang Y (2007) Using computerized provider order entry application to improve compliance with co-signature of verbal orders. AMIA Annu Symp Proc 1004. 
(c) (i)

This work is licensed under Creative

Commons Attribution 4.0 License

\section{Your next submission with Juniper Publishers} will reach you the below assets

- Quality Editorial service

- Swift Peer Review

- Reprints availability

- E-prints Service

- Manuscript Podcast for convenient understanding

- Global attainment for your research

- Manuscript accessibility in different formats

( Pdf, E-pub, Full Text, Audio)

- Unceasing customer service

Track the below URL for one-step submission https://juniperpublishers.com/online-submission.php 